\title{
Martial arts and combat sports theses and dissertations indexed in BASE database: a bibliometric approach
}

\author{
Mikel PÉREZ-GUTIÉRREZ* \& Carlos COBO-CORRALES \\ University of Cantabria (Spain)
}

8th IMACSSS International Conference Abstracts, Viseu (Portugal), October 10-12, 2019

Type: Oral communication

\begin{abstract}
The doctoral thesis is one of the most valued productions in a researcher's career. They are also an important source of information despite they are usually considered as grey literature due to their limited distribution. The aim of this work was to perform a bibliometric analysis of martial arts and combat sports (MA\&CS) doctoral or postdoctoral dissertations indexed in the Bielefeld Academic Search Engine (BASE) database. A comprehensive MA\&CS terms list and search strings were entered manually in the database search engine. Duplicate references were removed and obtained documents were filtered for meeting inclusion criteria. Selected references were then exported to Endnote X6 for classification and to Excel 2016 for bibliometric analyses. A total of 457 theses focused on MA\&CS, published from 1951 to 2019, were retrieved. The last analyzed decade collected $64.55 \%$ of total documents and judo was the most studied MA\&CS, with 90 documents. We conclude that MA\&CS theses and dissertations are an important source of information for scholars and academics, especially since the amount of them has considerably increased during the last decade at the international level.
\end{abstract}

Keywords: Martial arts; combat sports; scientific production; theses; bibliometrics.

\section{Introduction}

Grey literature is defined as those documents not available through regular market channels, and it is not widely distributed and/or controlled by commercial publishers (ABC-CLIO, 2019; Farace \& Schöpfel, 2010). To name a few, reports, newsletters, dissertations or conference proceedings, are document types usually considered as grey literature. Theses and dissertations, particularly at the doctoral level, are the "the first valuable document in the career of a researcher" (Stock \& Paillassard, 2010, p. 115) and an original piece of work compiling the result of, at least, three or four years of research. They show the research skills and competencies acquired by the $\mathrm{PhD}$ student, reflect the quality of the institution where the theses are defended. They are also a valuable source of information for professionals, scholars and/or academics (Stock \& Paillassard, 2010). Nowadays, Internet has promoted the dissemination, access and use of grey literature. The emergence of electronic theses and dissertations (ETDs) has solved the issues related to print theses regarding their archiving and circulation, becoming more accessible to users. Thus, several national and international initiatives have been developed for collecting print theses as well as ETDs (Stock \& Paillassard, 2010). Regarding martial arts and combat sports (MA\&CS), some works have been carried out for analyzing theses published in Spain (González, Sans-Rosell, Jové-Deltell, \& Reverter-Masia, 2018) and judo theses defended in Russian universities (Osipov, Kudryavtsev, Iermakov, \& Jagiełło, 2017) but, to the best of our knowledge, no studies have approached globally this topic at the international level.

\section{Objectives}

The aim of this study was to analyze martial arts and combat sports doctoral or postdoctoral theses and/or dissertations published in the BASE database, as a potentially relevant scientific source of information for scholars and academics within this field of knowledge.

*Email: mikel.perez@unican.es

(C) 2019 Universidad de León. www.unileon.es 


\section{Methodology}

Doctoral and postdoctoral theses relating to MA\&CS and published in the Bielefeld Academic Search Engine - BASE database (https://www.base-search.net/), pertaining to the Bielefeld University Library, until 2019 were included in the present study. MA\&CS were defined as any fighting, combat or wrestling style from any geographical origin, avoiding the Asianization of these terms (Green \& Svinth, 2010; Jimenez-Landazuri, Gomez-Alonso, Izquierdo, \& GutierrezGarcia, 2016). BASE database was selected as one of the world's most voluminous databases within the academic field, its free access and the possibility to export results to a reference manager software. The research included four phases. Firstly, a comprehensive list of MA\&CS terms including the different styles and spellings (Green \& Svinth, 2010; Pérez-Gutiérrez et al., 2013; Pérez-Gutiérrez, Gutiérrez-García, \& Escobar-Molina, 2011) was created. Secondly, MA\&CS terms were combined using the Boolean operator OR for creating several search strings and then, manually entered on the advanced search engine of BASE database. This search collected a total of 3,479 documents. Thirdly, results were exported to Endnote X6 reference manager software for deleting duplicates and checking the inclusion criteria. A total of 753 documents were duplicated while 2,269 did not met the inclusion criteria. Then, each document was classified according to the studied martial art/combat sport, as well as its decade of publication. Those documents referring to two or more MA\&CS were generally classified as MA\&CS. Finally, results were exported to Excel 2016 program for conducting the bibliometric analysis. This analysis was focused on the distribution of documents per year, decade and martial art/combat sport.

\section{Results and Discussion}

A total of 457 theses relating to MA\&CS, published from 1951 to 2019, were retrieved. The distribution of MA\&CS theses along time showed a progressive increase since the decade of the 1980s until now, with most theses being defended during the last decade (64.55\%). The emergence of Internet and later of ETDs have promoted the indexation and visibility of this kind of documents, but they are still considered as grey literature. Within the 22 different MA\&CS represented in our results, judo was the most analyzed MA\&CS with 90 documents, while 85 theses were dedicated to two or more MA\&CS. Capoeira, taijiquan and karate compiled 38, 37 and 36 theses respectively. On the other hand, shintaido, sumo or wing chun only collected one document respectively. These results emphasize the relevance of judo research within the academic field, but other disciplines such as taijiquan (27), capoeira (25) and taekwondo (20) have shown an important rise during the last decade.

\section{Conclusion}

MA\&CS theses and dissertations are an important source of information for scholars and academics, especially during the last decade with the broadening of MA\&CS represented and the increasing amount of thesis. Several theses and dissertations databases are available at the national and/or international level. They allow discovering, accessing and retrieving valuable information on MA\&CS, so they should be considered for MA\&CS research.

\section{References}

ABC-CLIO (2019). Gray literature. Retrieved 29/07/2019, from https://www.abcclio.com/ODLIS/odlis g.aspx

Farace, D. J., \& Schöpfel, J. (2010). Introduction. In D. J. Farace \& J. Schöpfel (Eds.), Grey Literature in Library and Information Studies (pp. 1-7). Berlin/New York: De Gruyter Saur.

González, V. H., Sans-Rosell, N., Jové-Deltell, C., \& Reverter-Masia, J. (2018). Bibliometric analysis of spanish doctoral thesis in martial arts and scientific publications of their authors. Movimento, 24(2), 367-382. doi: 10.22456/1982-8918.77660

Green, T. A., \& Svinth, J. R. (2010). Martial Arts of the World. An Encyclopedia of History and Innovation. Santa Barbara (CA): ABC-CLIO.

Jimenez-Landazuri, A., Gomez-Alonso, M. T., Izquierdo, E., \& Gutierrez-Garcia, C. (2016). Research into the history of martial arts and combat sports in Spain: The Noticiarios y documentales 
(No-Do - News newsreels (1943-1981). IDO Movement for Culture. Journal of Martial Arts Anthropology, 16(4), 11-20. doi: 10.14589/ido.16.4.3

Osipov, A. Y., Kudryavtsev, M. D., Iermakov, S. S., \& Jagiełło, W. (2017). Topics of doctoral and postdoctoral dissertations devoted to judo in period 2000-2016 - The overall analysis of works of Russian experts. Archives of Budo, 13, 1-10.

Pérez-Gutiérrez, M., Álvarez del Palacio, E., \& Gutiérrez-García, C. (2013). Repertorio bibliográfico anotado de monografías de artes marciales asiáticas publicadas en España. Revista de Artes Marciales Asiáticas, 8(1), 21. doi: 10.18002/rama.v8i1.836

Pérez-Gutiérrez, M., Gutiérrez-García, C., \& Escobar-Molina, R. (2011). Terminological recommendations for improving the visibility of scientific literature on martial arts and combat sports. Archives of Budo, 7(3), 159-166.

Stock, C., \& Paillassard, P. (2010). Theses and Dissertations. In D. J. Farace \& J. Schöpfel (Eds.), Grey Literature in Library and Information Studies (pp. 115-126). Berlin/New York: De Gruyter Saur. 